\title{
Planejamento familiar: perfil das usuárias de uma unidade de saúde de Curitiba
}

\author{
Family planning: profile of users in a health unit in Curitiba \\ La planificación familiar: perfil de los usuarios de una unidad de salud en Curitiba \\ Marciele Guimarães Fagundes ${ }^{1 *}$, Tânia Maria Santos Pires²
}

Palavras-chave: Planejamento Familiar

Gravidez

Educação em Saúde

\section{Resumo}

Este estudo almejou levantar o perfil reprodutivo e de planejamento familiar e as ferramentas utilizadas para concepção e contracepção, em mulheres em idade reprodutiva, evidenciando a importância das ações educativas relacionadas ao assunto. A coleta de dados sobre o padrão sexual e reprodutivo foi realizada por meio de um questionário desenvolvido com 14 perguntas fechadas, e aplicado no período de outubro a dezembro de 2007 a 355 mulheres de 15 a 49 anos da área de abrangência de uma unidade de saúde do município de Curitiba. Observou-se, dentre as mulheres sexualmente ativas, que: 33,8\% usavam pílula (dois terços menores de 30 anos), 25,1\% foram submetidas à laqueadura (quase 90\% com pelo menos 30 anos de idade), 9,5\% usavam injetáveis, 10,5\% utilizavam unicamente o preservativo e as demais tinham companheiros submetidos à vasectomia, usavam dispositivo intrauterino ou seguiam a 'tabelinha'. 9,8\% afirmavam não usar nenhum método e 79,8\% não usavam preservativo. 40,5\% das adolescentes sexualmente ativas utilizam preservativo. A maior fonte de aprendizado sobre anticoncepcionais são médicos ou enfermeiros (38,3\%), enquanto sobre planejamento familiar são familiares (20,8\%), embora 29\% responderam que ninguém as teria ensinado a respeito. Aproximadamente três quartos das entrevistadas desejavam até dois filhos e 48,7\% teriam dois filhos. Do somatório provável das gestações, 31,7\% foram declaradas planejadas, aquém do esperado. A primeira gestação foi a com maior porcentagem de planejamento, $36,7 \%$, das quais $71 \%$ ocorreram na idade adulta, seguida da segunda, com 32,5\%. Mais de um terço não planejou gestação alguma. Um total de 37,5\% de mulheres teve número de gestações que não extrapolam o desejado. A média estimada da menarca foi de 12,9 anos e 17\% afirmaram sexarca até os 14 anos. Das não-nuligestas e com história de uso de anticoncepcionais, mais de um quarto começaram contracepção somente após a primeira gestação. Houve proporcionalmente mais gestações relatadas do que o número desejado de filhos, quanto menor 0 grau de instrução. Pode-se notar que 0 conhecimento do planejamento familiar ainda não está bem difundido e 0 percentual de gestações consideradas planejadas é baixo e menor que 0 esperado. A proposta é investir em orientações e atividades em saúde, desde os dez anos, em ações de planejamento familiar que garantam o aprendizado dos indivíduos e a escolha informada do casal em prol de sua própria família.

Keywords: Family Planning (Public Health)

Pregnancy Health Education

\section{Abstract}

This study aimed at verifying the profile of reproductive and family planning and the tools used by reproductive age women to conception and contraception, indicating the importance of educational activities related to the subject. Data collection on sexual and reproductive pattern was conducted through a questionnaire with 14 questions developed and applied from October to December 2007 to 355 women 15-49 years-old from a health unit's area in Curitiba. It was observed, among sexually active women, that $33.8 \%$ used the pill (two thirds are under 30 years-old), $25.1 \%$ had undergone tubal ligation (almost $90 \%$ were at least 30 years-old), $9.5 \%$ used injectable

Pontifícia Universidade Católica do Paraná (PUC/PR). marcielevg@hotmail.com

2Pontifícia Universidade Católica do Paraná (PUC/PR). taninhaspires@hotmail.com

${ }^{\star}$ Autor correspondente.

Fonte de financiamento: nenhuma.

Conflito de interesses: declararam não haver.

Recebido em: 17/05/2011

Aprovado em: 04/11/2011 
contraception, only $10.5 \%$ used condoms, and the others had partners who had undergone vasectomy, used intrauterine device or followed the rhythm method. 9.8\% denied using any method and $79.8 \%$ did not use condoms. In addition, $40.5 \%$ of sexually active teens used condoms. The greatest source of learning about contraceptives are doctors or nurses (38.3\%), and concerning family planning are their relatives $(20.8 \%$ ), while $29 \%$ answered that nobody taught them about it. Around three quarters of respondents would have up to two children and $48.7 \%$ had two children. From the probable sum of all pregnancies, $31.7 \%$ were declared planned, less than what was expected. The first pregnancy was the champion of planning $(36.7 \%)$, of which $71 \%$ occurred in adulthood, followed by the second (32.5\% planned). More than a third did not plan any pregnancy, $37.5 \%$ of women did not have more pregnancies than they desired. The estimated average of menarche was 12.9 years-old and $17 \%$ reported first intercourse at 14 years-old. Of those who became pregnant and with a history of contraceptive use, over a quarter began contraceptive use only after the first pregnancy. Loweducation level was related to more pregnancies than the desired number of children. Knowledge of family planning is not welldistributed to the population, and the percentage of planned pregnancies is considered low and lower than expected. The proposal is to invest in guidelines and health activities about Family Planning for people since ten years-old to ensure individuals' learning and informed choice of couples in favor of their own family.

Palabras clave:
Planificación Familiar
Embarazo
Educación en Salud

\section{Resumen}

Este estudio tuvo como objetivo verificar el perfil de salud reproductiva y planificación familiar y las herramientas utilizadas por las mujeres en edad reproductiva de la concepción y la anticoncepción, lo que indica la importancia de las actividades educativas relacionadas con el tema. La recolección de datos en el patrón sexual y reproductivo se llevó a cabo a través de un cuestionario con 14 preguntas desarrollado y aplicado entre octubre y diciembre de 2007 a 355 mujeres de 15 a 49 años, del área de una unidad de salud en Curitiba. De ellos, se observó que el 33,8\% usaba la píldora (dos tercios son menores de 30 años de edad), el 25,1\% se habían sometido a la ligadura de trompas (casi el 90\% estaban en por lo menos 30 años de edad), un 9,5\% el uso de inyectables, sólo el 10,5\% usaba preservativos, y otras tienen compañeros que se habían sometido a la vasectomía, usaban el dispositivo intrauterino o seguían el método del ritmo, 9,8\% negaba el uso de cualquier método y un 79,8\% no usaba condón. 40,5\% de las adolescentes sexualmente activas utilizaban preservativos. La mayor fuente de aprendizaje acerca de los anticonceptivos son médicos 0 enfermeras $(38,3 \%)$, mientras que alrededor de la planificación familiar son sus familiares $(20,8 \%)$ y el $29 \%$ respondió que nadie les ha enseñado al respecto. Alrededor de tres cuartas partes de las encuestadas desean tener hasta dos niños y el $48,7 \%$ tuvo dos hijos. De la suma probable de todos los embarazos, el 31,7\% fueron declarados planificados, menos de lo esperado. El primer embarazo fue el campeón de la planificación (36,7\%), de los cuales $71 \%$ ocurrieron en la edad adulta, seguido por el segundo (32,5\% planificados). Más de un tercio no tenía previsto cualquier embarazo, el $37,5 \%$ de las mujeres no tenían más embarazos que se desee. El promedio estimado de la menarquía fue de 12,9 años y el 17\% informó de la primera relación sexual a los 14 años de edad. De las que se quedaron embarazadas y con el uso previo de anticonceptivos, más de un cuarto comenzó el uso de anticonceptivos sólo después del primer embarazo. Bajo nivel de educación se relacionó con más embarazos que el número deseado de hijos. El conocimiento de la planificación familiar no está bien distribuido a la población y el porcentaje de embarazos planeados se considera bajo y menor que lo esperado. La propuesta es investir en las directrices y actividades de salud sobre planificación familiar para personas desde dez años de edad para garantizar el aprendizaje de los individuos y la elección informada de las parejas en favor de su propia familia.

\section{Introdução}

Planejamento familiar "é o ato consciente de planejar o nascimento dos filhos, tanto em relação ao número desejado, quanto à ocasião mais apropriada de tê-los"1. É direito de todo cidadão " $\{\ldots\}$ e entende-se como o conjunto de ações de regulação da fecundidade que garanta direitos iguais de constituição, limitação ou aumento da prole pela mulher, pelo homem ou pelo casal"2.

A orientação é um elemento essencial para a qualidade de atenção em planejamento familiar. A ação educativa, realizada em pequenos grupos e usando metodologia participativa, tem como objetivo preparar e dar elementos para que as pessoas tenham uma opinião formada sobre seus direitos sexuais e reprodutivos e, principalmente, sobre as diferentes opções anticoncepcionais, de maneira que sejam capazes de realizar uma escolha livre e informada ${ }^{3}$. Apenas com o entendimento adequado dos métodos contraceptivos, as pessoas podem fazer escolhas informadas ${ }^{4}$.

O principal objetivo da orientação em planejamento familiar é facilitar o exercício de um dos direitos sexuais e reprodutivos, que é "o direito de decidir quantos filhos quer ter e quando tê-los”. Num sentido imediato, é auxiliar as pessoas para que tenham a oportunidade de discutir suas circunstâncias, necessidades e opções em relação à fertilidade e contracepção ${ }^{3}$. Mulheres orientadas, com maior nível educacional e emprego, são mais predispostas a usar contracepçãos

O método contraceptivo de maior sucesso é o que a mulher (ou o homem) escolhe $e^{6}$ Em geral, a mulher assume a responsabilidade pela contracepção, e o papel do parceiro é vivenciado como uma função acessória, apoio revelado pela aquisição da pílula, ação de lembrar a mulher de tomá-la ou opinião sobre o número de filhos desejado ${ }^{7}$.

No Brasil, a cada ano, cerca de $20 \%$ das crianças que nascem são filhas de adolescentes. Mesmo diante de casa- 
mentos ocorridos na adolescência de forma planejada e com gravidez também planejada, por mais preparado que esteja o casal, a adolescente não deixará de enfrentar a somatória das mudanças físicas e psíquicas decorrentes da gravidez e da adolescência ${ }^{8,9}$.

Na pesquisa de Manning, em 2000, 31\% dos adolescentes entrevistados não usaram método contraceptivo na primeira relação sexual; $52 \%$ dos que tinham recém conhecido seu parceiro não usaram nenhum método; $75 \%$ usaram camisinha como contraceptivo na primeira relação e $17 \%$, a pílula ${ }^{10}$. A maioria dos adolescentes, conforme Zenevicz e Fernandes, não utiliza preservativos, apesar de conhecerem sua importância, havendo incoerência entre o conhecimento e a utilização, fato que afeta a qualidade de vida dos mesmos ${ }^{11}$. A desculpa frequentemente encontrada para o não-uso da contracepção é não ter relações sexuais frequentes e depender do método do ritmo ${ }^{12}$.

Possivelmente graças à informação e à conscientização sobre os riscos e as consequências trazidos pela gravidez durante a adolescência, em São Paulo houve diminuição de $40 \%$ de grávidas adolescentes em dez anos. Em 2008, as adolescentes grávidas representaram $15,7 \%$ do total de partos, índice que, em 2002, era de $18,4 \%{ }^{13}$.

Os profissionais, segundo pesquisa de Araújo, consideram a educação em saúde em Planejamento Familiar importante. Porém, apesar de empenho e vontade de acertar, há falta de capacitação técnica, política e pedagógica, bem como limitação de material didático para a sua consecução. São necessárias capacitações, favorecendo o desenvolvimento de ações educativas com abordagens participativas e problematizantes, de forma a oportunizar discussões que promovam reflexão crítica do grupo com troca de saberes para aquisição de autonomia e maturidade, garantindo direito de escolha ${ }^{14}$.

Para um programa de saúde sexual ser ideal, segundo Sadovsky, na percepção de adultos jovens, deve haver uma pessoa acessível e não-temível para ensiná-los assuntos peculiares sobre doenças sexualmente transmissíveis (DST) com mais detalhes, o que fazer para se protegerem e controlar natalidade e como funciona o sistema reprodutivo $^{15}$. Um estudo de Lindsay concluiu que prover os pais de informação sobre saúde sexual pode ajudar a melhorar a saúde sexual dos jovens, pois a pesquisa revelou que a maior fonte de informações sobre contracepção e DSTs foi: pais seguidos de médicos e professores para contracepção, e professores e, então, médicos para DSTs ${ }^{16}$. Já Thiebaux pesquisou a preferência de gestantes sobre o método de aprendizagem: $48 \%$ selecionaram como primeira ou segunda escolha um curso compreensivo de saúde, com franca apresentação sobre sexualidade e contracepção; o pró- ximo método mais escolhido foi discussão individual; e grupo de discussão com outros jovens também foi um dos preferidos. A escola foi escolhida por $35 \%$ como o local de aprendizado e $30 \%$ preferiram a casa ${ }^{12}$.

De acordo com Lyra (2000), a Sociedade Civil de Bemestar Familiar no Brasil (BEMFAM) de 1992 aponta que $46 \%$ das mulheres em Curitiba não planejavam a gravidez ${ }^{17}$. Dados da Pesquisa Nacional de Demografia e Saúde (PNDS), de 1990 a 1995, demonstram que 50\% das mulheres brasileiras que tiveram filhos não planejaram a gravidez $^{18}$. Estudo da Universidade Federal do Paraná ${ }^{19}$, em 2006, encontrou que 46\% de 67 mulheres mães de crianças que frequentavam creches, e com nível socioeconômico baixo, não planejaram a gravidez daquele filho. Em Cascavel ${ }^{20}$, em 2005, planejaram a gravidez $61,7 \%$ de 493 mães entrevistadas.

Segundo o protocolo de atenção à saúde do adolescente ${ }^{21}$, numa pesquisa realizada em escolas de Curitiba e Região Metropolitana, em 1998, a idade média da iniciação sexual para meninos foi de 14,6 anos e de 15,6 anos para as meninas. O tempo entre a primeira relação sexual e a procura dos serviços de saúde costuma ser de vários meses. Nos EUA, a média é de 12 meses, sendo que $50 \%$ das gestações ocorrem nos primeiros seis meses do início da atividade sexual, com uma estimativa de que 25 a $50 \%$ dos adolescentes não usam qualquer tipo de contraceptivo na primeira relação sexual, e que $50 \%$ deles descontinuam o método nos primeiros três meses de uso.

Torna-se importante revisar a utilização do planejamento familiar por cada comunidade e promover ações educativas criativas e eficientes, que estimulem os usuários a escolherem seu próprio método ou momento de reprodução e contracepção, o que é direito individual ou do casal.

O presente estudo teve como objetivo buscar o perfil reprodutivo e de planejamento familiar da população feminina em idade reprodutiva, inscrita no Programa Saúde Integral da Mulher da Unidade Municipal de Saúde (UMS) Osternack, a qual pertence ao Distrito Sanitário Bairro Novo, da Secretaria Municipal de Curitiba. Esse programa pertence às Unidades Municipais de Saúde de Curitiba.

Aventou-se buscar como ocorre seu comportamento sexual (envolvendo menarca, sexarca e início da contracepção) e quais são as ferramentas (fontes de orientação sobre Planejamento Familiar, métodos contraceptivos) utilizadas por essa população para garantir o direito de escolher o momento da concepção e da contracepção.

As finalidades subsequentes do trabalho, tomando por base o padrão de Planejamento Familiar apresentado por essa população, foram evidenciar a importância da implementação de ações educativas programadas ine- 
rentes ao Planejamento Familiar - informação em saúde sexual e reprodutiva - numa comunidade como esta, e observar qual idade predomina o início da atividade sexual para sugerir a faixa etária para iniciar a abordagem do tema e qual ambiente seria mais apropriado para tanto, conforme a cultura presente no local.

\section{Materiais e métodos}

A pesquisa possui característica descritiva, de corte transversal, e teve como instrumento para a coleta de dados um questionário de perguntas fechadas, que foi aplicado a uma amostra significativa de participantes. Selecionou-se a amostra randomicamente, dentre mulheres de 15 a 49 anos e inscritas como usuárias no Programa Saúde Integral da Mulher da UMS Osternack, por intermédio de listagem disposta no Prontuário Eletrônico.

O projeto de pesquisa recebeu aprovação pelo Comitê de Ética em Pesquisa da Pontifícia Universidade Católica do Paraná (CEP PUC/PR), em julho de 2007, conforme registro do projeto do CEP PUC/PR 1895 e parecer do protocolo de pesquisa $n^{\circ} 397 / 07$, no cumprimento da Resolução 196/96. O trabalho não obteve financiamento e não sofreu conflito de interesses.

O número da amostra foi calculado pela fórmula ${ }^{22}$ para amostras de populações finitas (quando a população não supera 100.000 elementos), com base no número total de mulheres de 15 a 49 anos, cadastradas no Programa de Saúde Integral da Mulher da UMS Osternack, que está disponível em relatório do Prontuário Eletrônico utilizado pela Prefeitura Municipal de Curitiba (3.285 mulheres, conforme relatório de 22 de junho de 2007). Foi aceito o nível de confiança de $95 \%$ e o erro máximo de $5 \%$, e considerou-se que o fenômeno de ausência de planejamento familiar se verifica em $46 \%$ da população de Curitiba.

Precisariam ser incluídas na pesquisa, pelo cálculo de amostra para populações finitas, pelo menos 355 mulheres de 15 a 49 anos, com cadastro no Programa Saúde Integral da Mulher da UMS Osternack. Foram excluídas mulheres que não correspondiam à faixa etária selecionada, que vivessem na mesma casa de outra mulher que já havia sido entrevistada e em caso de recusa (por parte da mulher selecionada ou de seu responsável legal) a responder ao questionário. As perdas foram estimadas em $10 \%$ e constituíram mulheres não-encontradas na UMS ou em domicílio, no período destinado à coleta de dados. Estas foram substituídas por moradoras atuais do local da residência de usuária não-encontrada ou por outras usuárias também escolhidas randomicamente.
Esse questionário foi elaborado pela autora e reestruturado após aplicação de um piloto semelhante. Compreende-se um número de 15 perguntas objetivas que, além de incluírem identificação e nível de escolaridade e ocupação, estão relacionadas ao comportamento reprodutivo e às fontes utilizadas pelas pessoas para obter informações que motivaram seu próprio Planejamento Familiar. As demais questões levantam os sujeitos e ambientes citados pelas participantes como fonte principal de aprendizagem sobre o tema Planejamento Familiar.

A aplicação do questionário foi realizada de outubro a dezembro de 2007, e foi precedida de leitura e assinatura por cada participante ou responsável do termo de consentimento livre e esclarecido. O preenchimento do questionário foi realizado onde a usuária foi mais facilmente encontrada, em visita domiciliar realizada com auxílio das Agentes Comunitárias de Saúde ou na própria Unidade de Saúde, individualmente, supervisionado somente pela autora, e preenchido por esta em caso de respondente analfabeta.

Os dados colhidos pelo questionário foram tabulados e analisados com auxílio de tabelas do Microsoft Excel 2002.

\section{Resultados}

Foi aplicado o questionário a uma população de $355 \mathrm{mu}$ lheres de 15 a 49 anos, com média de idade de 30 anos. $75,5 \%$ são casadas e 8,5\% estão namorando, totalizando $84 \%$ de mulheres com parceiro, porém não necessariamente com relações sexuais. Essa população se compõe de 2,5\% de analfabetas, 1,9\% possuem Ensino Superior e outras 63,4\% teriam estudado no máximo até a oitava série do Ensino Fundamental. Mais da metade das entrevistadas se declararam do lar e 6,7\% são estudantes.

A respeito do método anticoncepcional (MAC) em uso, percebe-se, na Tabela 1, que das 355 mulheres entrevistadas, 58 responderam não ter relações sexuais (logo, $83,7 \%$ do total seriam sexualmente ativas) e 6,2\% não faziam uso de MAC, mas com uma justificativa, pois se declararam gestantes, puérperas ou tentando engravidar. Dentre as demais 275 mulheres, quase $10 \%$ negaram uso de MAC no período da entrevista.

Separando abstinentes, sem sexarca e com justificativa para não utilizar métodos contraceptivos, ficou-se, então, com 275 mulheres: 9,8\% afirmaram não usar qualquer método; $33,8 \%$ usavam a pílula ou os anticoncepcionais hormonais orais (ACHO) (18 também usam preservativo); 25,1\% foram submetidas à laqueadura tubária (LT); 9,5\% usavam anticoncepcionais injetáveis (ACI) (duas também usam preservativo); $10,5 \%$ utilizavam somente o preservativo; $5,8 \%$ tinham seus companheiros submetidos à vasectomia; $4,7 \%$ usavam 
dispositivo intrauterino (DIU) e 0,7\% seguiam o método da tabelinha (uma também com preservativo).

De 248 participantes sexualmente ativas que marcaram uso de um ou dois MAC, 79,8\% não selecionaram a camisinha, que é utilizada como método exclusivo por $11,7 \%$ e complementar por $8,5 \%$ das mesmas 248 mulheres. Nesta população, os MAC mais prevalentes perante as usuárias são: o $\mathrm{ACHO}$, com $37,5 \%$, e a LT, com $25,0 \%$ dos métodos utilizados.

Dentre as mulheres que utilizam ACHO, 64,6\% têm idade menor que 30 anos e $88,4 \%$ das submetidas à LT possuem pelo menos 30 anos de idade, e a prevalência deste último método aumenta com a idade. Quanto às usuárias de ACI, 61,5\% são menores de 30 anos. Não há faixa etária predominante para uso de DIU, tabelinha ou de nenhum método.

Correlacionando-se com estado conjugal, das $298 \mathrm{mu}-$ lheres que moram com companheiro ou namorando, $2 \%$ seriam abstinentes e $9 \%$ negaram o uso de MAC no decorrer de sua vida.

À entrevista, $32(55,2 \%)$, dentre 58 adolescentes de 15 a 19 anos (a Organização Mundial da Saúde e o Ministério da Saúde conceituam adolescência dos 10 aos 20 anos incompletos $^{21}$ ), eram nuligestas e, ao visualizar a Tabela 2, 13 $(22,4 \%)$ adolescentes não tiveram sua sexarca, ao passo que somente duas respondentes adultas se declararam virgens. Retirando-se abstinentes sexuais, gestantes e puérperas lactantes, restam 37 com vida sexual ativa e que deveriam, teoricamente, usar algum tipo de MAC. Cinco (13,5\%), por conseguinte, negaram uso de MAC, enquanto as demais estariam em uso de ACHO, preservativos, ACI ou DIU. Ao todo, 15 usam a camisinha, contemplando $40,5 \%$ das adolescentes sexualmente ativas.

Quanto à fonte de aprendizado sobre MAC, 38,3\% referiram ter aprendido sobre MAC com médicos ou enfermeiros, $16,6 \%$ com o pai ou a mãe, $12,7 \%$ com professores, $10,1 \%$ com amigos, e uma parcela menor com outros familiares, televisão, leitura ou igreja. Os demais $7,3 \%$ marcaram não ter aprendido sobre MAC com ninguém.

Dentre as entrevistadas, $75,8 \%$ gostariam de ter até dois filhos (6,5\% não teriam nenhum filho, $20,6 \%$ teriam um e $48,7 \%$ teriam dois); $23,1 \%$ desejam três ou mais filhos e as demais não responderam. Maior percentual relativo das que desejam até dois filhos se encontra entre as que obtiveram informações sobre Planejamento Familiar antes dos 13 anos de idade, compreendendo 86,0\%. Esse percentual é menor nas que obtiveram informações somente mais tarde.

Quase 20\% das respondentes tiveram quatro gestações ou mais e as nuligestas compreendem 12,7\%. Conforme a Tabela 3, o maior número de gestações é proporcional à idade que a mulher apresenta. Das que tiveram pelo menos três filhos, $74,6 \%$ tinham idade maior ou igual a 30 anos.
A pesquisa revelou que 310 mulheres $(87,3 \%)$ já haviam engravidado, dentre as quais $16,8 \%$ planejaram e $38,4 \%$ negaram ter planejado quaisquer de suas gestações. Foi planejada uma gravidez por $49,7 \%$ e duas por $8,4 \%$. Contando o somatório provável das gestações, $31,7 \%$ foram declaradas planejadas.

Tabela 1. Métodos anticoncepcionais em uso pelas entrevistadas.

\begin{tabular}{lcc}
\hline Métodos anticoncepcionais em uso & $\mathrm{n}$ & $\%$ \\
\hline Pílula & 75 & 21,1 \\
Laqueadura & 69 & 19,4 \\
\hline Camisinha & 29 & 8,2 \\
\hline Injetável & 24 & 6,7 \\
\hline Pílula + Camisinha & 18 & 5,1 \\
Vasectomia & 16 & 4,5 \\
\hline DIU & 13 & 3,7 \\
Injetável + Camisinha & 2 & 0,5 \\
\hline Tabelinha + Camisinha & 1 & 0,3 \\
\hline Tabelinha & 1 & 0,3 \\
\hline Nenhum & 27 & 7,6 \\
Nenhum - Gestante & 16 & 4,5 \\
\hline Nenhum - Puerpério & 5 & 1,4 \\
\hline Nenhum - Quer engravidar & 1 & 0,3 \\
\hline Abstinência sexual & 35 & 9,9 \\
\hline Abstinência + Laqueadura & 11 & 3,1 \\
\hline Abstinência + Pílula & 6 & 1,7 \\
\hline Abstinência + Injeção & 6 & 1,7 \\
\hline Total & 355 & 100 \\
\hline
\end{tabular}

Tabela 2. Correlação entre método anticoncepcional em uso e idade da sexarca das adolescentes.

\begin{tabular}{|c|c|c|c|c|c|c|}
\hline \multirow{2}{*}{$\begin{array}{l}\text { Método } \\
\text { anticoncepcional } \\
\text { sendo utilizado pelas } \\
\text { adolescentes }\end{array}$} & \multicolumn{4}{|c|}{ Idade na sexarca (anos) } & \multirow{2}{*}{$\mathrm{n}$} & \multirow{2}{*}{$\%$} \\
\hline & $<15$ & $15-17$ & $18-20$ & Nunca & & \\
\hline Abstinência sexual & 1 & 3 & 0 & 13 & 17 & 29,3 \\
\hline Pílula & 3 & 4 & 1 & 0 & 8 & 13,8 \\
\hline Camisinha & 4 & 4 & 1 & 0 & 9 & 15,5 \\
\hline Pílula + Camisinha & 3 & 2 & 0 & 0 & 5 & 8,6 \\
\hline Injetável & 2 & 4 & 0 & 0 & 6 & 10,3 \\
\hline Injetável + Camisinha & 0 & 0 & 1 & 0 & 1 & 1,7 \\
\hline DIU & 1 & 0 & 0 & 0 & 1 & 1,7 \\
\hline Nenhum - Gestante & 1 & 2 & 0 & 0 & 3 & 5,2 \\
\hline Nenhum - Puerpério & 2 & 1 & 0 & 0 & 3 & 5,2 \\
\hline Nenhum & 2 & 3 & 0 & 0 & 5 & 8,6 \\
\hline Total & $19(32,8 \%)$ & $23(39,6 \%)$ & $3(5,2 \%)$ & $13(22,4 \%)$ & 58 & 100 \\
\hline
\end{tabular}

Tabela 3. Número declarado de gestações versus idade das participantes.

\begin{tabular}{|c|c|c|c|c|c|c|c|c|}
\hline \multirow{2}{*}{$\begin{array}{l}\text { Número de } \\
\text { gestações }\end{array}$} & \multicolumn{6}{|c|}{ Idade } & \multirow{2}{*}{$\mathrm{n}$} & \multirow{2}{*}{$\%$} \\
\hline & $15-19$ & $20-24$ & $25-29$ & $30-34$ & $35-39$ & $40-49$ & & \\
\hline Nenhuma & 32 & 6 & 4 & 2 & 1 & 0 & 45 & 12,7 \\
\hline 1 & 22 & 24 & 13 & 3 & 10 & 1 & 73 & 20,6 \\
\hline 2 & 4 & 12 & 24 & 25 & 16 & 18 & 99 & 27,9 \\
\hline 3 & 0 & 3 & 14 & 20 & 14 & 17 & 68 & 19,1 \\
\hline 4 ou mais & 0 & 2 & 16 & 9 & 16 & 27 & 70 & 19,7 \\
\hline Total & 58 & 47 & 71 & 59 & 57 & 63 & 355 & 100 \\
\hline
\end{tabular}


A primeira gestação foi a campeã de planejamento, com $36,7 \%$, seguida de $32,5 \%$ da segunda, e apenas $25,4 \%$ da terceira. Não se pode ter um percentual exato a partir da quarta gestação a partir do questionário aplicado. Para $71 \%$ que planejaram a primeira gestação, engravidaram pela primeira vez na idade adulta. Houve 38,4\% (119 de 310 mulheres com história de gestação) que não planejaram nenhuma de suas gestações.

Questionando-se a fonte de aprendizado, 29,0\% das entrevistadas responderam que ninguém as teria ensinado a respeito, um número alto, considerando-se a dificuldade de compreensão da pergunta ou do conceito de Planejamento Familiar. Neste ponto, também é encontrado um problema de entendimento, pois um terço daqueles $29,0 \%$ checou uma idade de primeiras informações sobre o assunto.

Uma fonte positiva de aprendizado foi selecionada por 241 mulheres. As maiores fontes são familiares (20,8\%), tendo sido a mãe e o marido os mais citados, e depois médicos ou enfermeiros $(17,2 \%)$ - estas, cujas maiores fontes foram médicos ou enfermeiros, receberam informações sobre Planejamento Familiar proporcionalmente mais tarde: $55,2 \%$ obtiveram as primeiras informações quando maiores de idade.

Das que foram informadas sobre Planejamento Familiar desde os 12 anos de idade, 30\% (maior percentual) citaram algum familiar, $20 \%$ marcaram "ninguém" e 18\%, professores. Das que só obtiveram informações a partir dos 18 anos, 33,7\% tiveram como maior fonte os médicos ou enfermeiros e $29,4 \%$ destas engravidaram antes de obter (ou nunca tiveram) informações.

$\mathrm{Na}$ Tabela 4 observa-se que 18,6\% revelaram nunca ter recebido qualquer informação sobre Planejamento Familiar, 28,4\% apenas na idade adulta, $14 \%$ até 12 anos de idade e $35,5 \%$, dos 13 aos 17. Doze não souberam responder. Cinquenta indivíduos foram informados sobre Planejamento Familiar até os 12 anos,

Tabela 4. Fonte e idade de primeiras informações sobre Planejamento Familiar.

\begin{tabular}{lrrrrrrrr}
\hline \multirow{2}{*}{$\begin{array}{l}\text { Com quem aprendeu sobre } \\
\text { Planejamento Familiar }\end{array}$} & $\begin{array}{c}\text { Idade das primeiras informações sobre } \\
\text { planejamento familiar }\end{array}$ & $\mathrm{n}$ & $\%$ \\
\cline { 2 - 7 } & $<13$ & $13-17$ & $>17$ & Não sei & Não tive & \\
\hline Ninguém & 10 & 13 & 12 & 2 & 66 & 103 & 29,0 \\
Familiar & 15 & 37 & 21 & 1 & 0 & 74 & 20,8 \\
\hline Médicos/Enfermeiros & 2 & 24 & 34 & 1 & 0 & 61 & 17,2 \\
\hline Amigos & 7 & 16 & 11 & 1 & 0 & 35 & 9,9 \\
\hline Professores & 9 & 17 & 1 & 2 & 0 & 29 & 8,2 \\
\hline Televisão & 1 & 3 & 10 & 2 & 0 & 16 & 4,5 \\
Leitura & 3 & 4 & 6 & 0 & 0 & 13 & 3,7 \\
Igreja & 1 & 3 & 2 & 1 & 0 & 7 & 1,9 \\
Grupos & 1 & 3 & 0 & 0 & 0 & 4 & 1,1 \\
Vizinhos & 0 & 1 & 1 & 0 & 0 & 2 & 0,6 \\
Não sei & 1 & 5 & 3 & 2 & 0 & 11 & 3,1 \\
Total & 50 & 126 & 101 & 12 & 66 & 355 & 100 \\
\hline & & & & & & & \\
\hline
\end{tabular}

sendo que quase metade está com idade atual de 15 a 19 anos, o que representa 39,6\% das mulheres nessa faixa etária, um percentual bem maior do que entre as mais velhas.

Além disso, dessas que começaram a aprender sobre Planejamento Familiar antes dos 13 anos, 30,0\% citaram como fonte algum familiar (o maior percentual), 20,0\% marcaram ninguém e $18,0 \%$, os professores. Das que o tiveram na idade adulta, 33,7\% tiveram médicos ou enfermeiros como maior fonte, $20,8 \%$ aprenderam mais com familiares e 11,9\% com ninguém. Uma hipótese foi aventada, antes da averiguação dos dados, na suposição de que as mulheres que aprenderam mais tarde e, principalmente com médicos ou enfermeiros, teriam sido informadas sobre Planejamento Familiar somente após terem engravidado. Encontrou-se, nessa situação, que $31,3 \%$ engravidaram certamente antes da primeira informação sobre Planejamento Familiar.

Descontando algumas mulheres que não souberam responder a idade das primeiras informações sobre Planejamento Familiar, há 45 mulheres que não planejaram nenhuma de suas três ou mais gestações e foi possível notar que $37,8 \%$ receberam informações somente na idade adulta e $28,9 \%$ nunca receberam. Assim, as que tiveram mais gestações e não-planejadas obtiveram informações mais tarde ou não as obtiveram.

A média estimada da menarca dessas usuárias é de quase 13 anos (12,9 anos). Contudo, é preciso mencionar que $45,6 \%$ das entrevistadas tiveram sua primeira menstruação até os 12 anos de idade e $5 \%$ até os 10 . Ademais, 340 afirmaram sexarca e, destas, $63,5 \%$ antes dos 18 anos de idade. $\mathrm{Na}$ presente pesquisa, $17 \%$ afirmaram sexarca até os 14 anos.

Das mulheres com sexarca referida, $50 \%$ somente iniciariam uso de MAC com idade superior à da primeira relação sexual, 6,5\% nunca utilizaram MAC e 34,34\% iniciaram uso de MAC até os 17 anos de idade. Além disso, 54,2\% daquelas que iniciaram atividade sexual antes da maioridade, também começaram MAC nessa mesma época da vida.

Após a exclusão de nuligestas e de quem negou ter recebido informações sobre Planejamento Familiar, têm-se 240 respondentes e pelo menos um quarto certamente teve sua primeira gestação sem antes ter utilizado algum MAC ou, ainda, nunca chegaram a usar. Estranho este fato ter sido mais evidente dentre as que receberam informações antes dos 13 anos de idade. Excluindo apenas as nuligestas e permanecendo 310 mulheres, $36,6 \%$ obtiveram informações sobre Planejamento Familiar antes da primeira gravidez. Das que já engravidaram uma ou mais vezes e com história de uso de MAC, em torno de 30,0\% começaram uso de MAC somente após a primeira gravidez.

Conforme mencionado, 310 já estiveram grávidas e, para $36,8 \%$ desse total, a primeira gestação ocorreu antes 
da maioridade. Analisando-se a Tabela 5, mais da metade $(52,3 \%)$ de quem teve sua sexarca até os 17 anos engravidou até esta idade. Destas, que somam 113, 29,2\% planejaram a primeira gravidez.

É possível inferir que o planejamento já foi alcançado integralmente por $7,6 \%$ das mulheres entrevistadas, ou seja, elas tiveram o número de gestações desejadas exatamente igual a quantas vezes ficaram grávidas e à quantidade de gestações previamente planejadas. Por exemplo, se queriam zero, um ou dois filhos, tiveram e planejaram os mesmos, e praticamente a metade $(44,4 \%)$ dessas usuárias possui idade entre 15 e 24 anos.

O número almejado de gestações ainda pode ser alcançado por 29,9\% de mulheres, que até o momento possuem um número menor de gestações do que a quantidade de filhos desejada. Totalizou-se, portanto, $37,5 \%$ de gestações que não extrapolam o desejado. Uma controvérsia, contudo, foi evidenciada na pesquisa, quando quatro mulheres referiram uma gravidez planejada dentre três ou mais e anotaram não desejarem filhos.

A educação certamente influenciou a quantidade de gestações de cada participante da pesquisa. Perante as $70 \mathrm{mu}-$ lheres que tiveram mais de três gestações, $45,7 \%$ eram de escolaridade nula ou até a quarta série $(29,9 \%$, ponderando pelo número de pessoas por escolaridade) e mais de $90 \%$ estudaram no máximo até a oitava série ou são analfabetas. Conclui-se que tiveram proporcionalmente mais gestações relatadas que o número desejado de filhos quanto menor o grau de instrução, inferindo-se que, mesmo considerando a possibilidade de o número de gestações ser diferente daquele existente de filhos, as menos instruídas conceberam mais filhos do que gostariam.

Por sua vez, pode-se perceber que a quantidade de filhos desejada é menor quanto maior for a escolaridade, válido para mais de três filhos, pois todas as participantes com Ensino Superior gostariam de ter dois ou três filhos e, ao mesmo tempo, possuem menos gestações que o número desejado de filhos.

\section{Discussão}

"Sabe-se que pelo menos metade das gestações não são inicialmente planejadas, embora possam ser desejadas" 23 . A presente pesquisa encontrou que $31,7 \%$ das gestações declaradas pelas entrevistadas teriam sido planejadas, embora $61,6 \%$ das entrevistadas tenham citado que planejaram ao menos uma de suas gestações. Esses dados não poderiam ser comparados à média de planejamento apontada pelo BEMFAM ${ }^{17}$.
Tabela 5. Relação entre sexarca e idade da primeira gestação.

\begin{tabular}{|c|c|c|c|c|c|c|c|c|c|c|c|c|}
\hline \multirow{2}{*}{$\begin{array}{l}\text { Idade da } \\
\text { sexarca }\end{array}$} & \multicolumn{10}{|c|}{ Idade na primeira gestação (anos) } & & \multirow{2}{*}{$\%$} \\
\hline & 12 & 13 & 14 & 15 & 16 & 17 & 18 & 19 & $>19$ & nunca & & \\
\hline$<15$ ano & 1 & 5 & 5 & 1 & 4 & 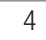 & 4 & 2 & 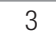 & 8 & 59 & 27,3 \\
\hline $15-17$ ar & 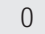 & 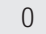 & 0 & 12 & 24 & 35 & 23 & 14 & 33 & 16 & 157 & 72,7 \\
\hline Total & 1 & 5 & 15 & 25 & 28 & 39 & 27 & 16 & 36 & 24 & 216 & 100 \\
\hline
\end{tabular}

Sabe-se que a sexarca tem sido cada vez mais preco$\mathrm{ce}^{24}$. Artigo de $\mathrm{Cardozo}^{25}$ demonstrou que a idade média de início da atividade sexual em Salvador seria 15 anos e 9 meses, com registros de iniciativas também entre 10 e 12 anos de idade.

A sexarca de 15,6 anos (pelo protocolo de atenção à saúde do adolescente, de Curitiba e Região) e a presente pesquisa, que informou $17 \%$ com sexarca até os 14 anos, início de uso de MAC após a primeira gravidez por 30,0\% e gravidez antes de ser informadas sobre Planejamento Familiar por $31,3 \%$, sugerem necessidade de orientação. Ainda, 38,4\% (119 de 310 mulheres com história de gestação) não planejaram nenhuma de suas gestações, assume-se que exista falta de informação eficaz sobre Planejamento Familiar.

Por ser uma grande preocupação da saúde pública evitar gestações não programadas, há necessidade de prover à população ferramentas para que promova seu próprio planejamento. O maior desafio é aplicar metodologia adequada para abordagem do tema, visando melhor aceitação da informação e real mudança de atitude perante o conhecimento adquirido. Conforme conclusão de Topsever, as estratégias e o conteúdo do aconselhamento devem ser reestruturados para melhor eficácia ${ }^{26}$.

A gravidez na adolescência vem sendo considerada em alguns países como um problema de saúde pública, uma vez que pode acarretar complicações obstétricas, com repercussões para a mãe e o recém-nascido, bem como problemas psicossociais e econômicos ${ }^{9}$. Pode resultar na perda de liberdade, adiamento ou comprometimento dos projetos de estudos, limitação de perspectivas de ingresso no mercado de trabalho e diminuição do aproveitamento pleno das oportunidades para completo desenvolvimento pessoal, tornando as opções de vida e oportunidades reduzidas ${ }^{27}$.

Vários fatores são apontados para a ocorrência da gestação na adolescência. Até há cerca de duas décadas, somavase a estes a possível falta de informação. Posteriormente, a literatura mostrou-se plena de estudos que mostravam o contrário: adolescentes tinham a informação sobre métodos anticoncepcionais, mas não os utilizavam por várias razões ${ }^{28}$. De acordo com um estudo de Belo e Silva, por exemplo, $54 \%$ das adolescentes usaram algum contraceptivo na primeira relação sexual e houve um período de tempo curto entre o início da vida sexual e a gravidez ${ }^{27}$. 
Dados obtidos pelo Prontuário Eletrônico utilizado pela UMS em questão informam que no período de um ano, de junho de 2006 a maio de 2007, $11 \%$ de 314 gestações inscritas no período ocorreram em mulheres com idade menor que 15 anos e acima de 35 anos. Entretanto, é difícil encontrar conhecimento já estabelecido sobre quais gestações, inclusive dentre mulheres entre 15 e 35 anos, foram, ou não, programadas previamente e quais métodos contraceptivos estão sendo utilizados para evitar gravidez indesejada. Esta última informação poderia ser fornecida pelo Prontuário Eletrônico caso fosse bem notificada em campo apropriado e ficassem disponíveis os dados gerados em relatório.

Os resultados da pesquisa sugerem que o número de filhos desejado sofre influência da inclusão progressiva da carreira profissional feminina e da cultura atual. Além disso, ao correlacionar número desejado de filhos e idade com que recebeu as primeiras informações sobre planejamento familiar, pôde-se observar que as mulheres que obtiveram informações mais cedo (até os 12 anos), desejam uma menor quantidade de filhos. Presume-se que as mais jovens já estejam adquirindo melhor domínio no momento de decidir e controlar seu número de gestações, de acordo com as respostas obtidas.

Também curioso foi o fato de que entre as que não teriam filhos, quase metade já havia engravidado quatro ou mais vezes, aventando questionamentos quanto à causalidade deste dado. A prevalência do uso de MAC, por sua vez, foi confirmada, de acordo com as expectativas da literatura ${ }^{29-30}$, sendo o primeiro o ACHO e o segundo a LT.

Nesta pesquisa, a despeito de o preenchimento do questionário ter sido supervisionado, principalmente no momento de dúvidas, considerou-se vieses de memória ao responder idades pontuais e de compreensão, com provável dificuldade em conceito individual de Planejamento Familiar e confusão para se diferenciar entre Planejamento Familiar e MAC ou entre número desejado de filhos e quantidade real deles. Diversas mulheres incluíram idade de informações sobre Planejamento Familiar sem selecionar uma fonte principal de aprendizado sobre isso. Houve mulheres que marcaram usar MAC e, ao mesmo tempo, estariam solteiras, separadas ou viúvas e sem namorado.

A análise poderia ser facilitada com a inclusão de algumas perguntas sobre vida sexual ativa, quantos filhos têm e quantos abortos já sofreram. Mesmo assim, extensos resultados puderam ser coletados e o perfil de planejamento familiar foi acessado. Algumas respondentes se queixaram de certa dificuldade para acessar consultas para orientação contraceptiva, que concorrem, em desvantagem, com o atendimento de demanda e a alguns MAC.

\section{Conclusão}

Urge um andamento consciente de ideias que promovam o programa de Planejamento Familiar, com ênfase em orientações palpáveis e adequadas à realidade e ao entendimento dos pacientes.

Em tal raciocínio, surge o questionamento de como nós, profissionais da saúde, orientamos sobre planejamento familiar (e de vida). Será que, em nossas consultas, apenas lembramos, quando muito, de orientar nossos pacientes sobre MAC ou simplesmente prescrevemos uma "pílula"? Mal explicamos sobre modo de uso, quanto menos propomos ao paciente sua própria decisão, após supostamente termos oferecido informações necessárias que proporcionem uma escolha realmente informada.

Pelo fato de aproximadamente $45 \%$ das entrevistadas terem tido sua menarca até os 12 anos e quase $20 \%$ tiveram sexarca antes dos 14 anos, torna-se interessante o investimento em orientações em saúde sexual e reprodutiva a partir dos dez anos. A ideia é promover a educação em sexualidade e o planejamento familiar, com início precoce e de maneira continuada, diretamente às crianças e a seus pais e professores, tanto no ambiente da escola quanto em ações em saúde da UMS em consultas ou reuniões de grupo.

Com os resultados apresentados, torna-se bastante válido o investimento em projetos de educação em saúde condizentes ao Planejamento Familiar, incluindo capacitação dos profissionais, que aprimorem o aprendizado dos casais, a fim de que estes busquem conscientemente o planejamento de suas próprias famílias.

\section{Referências}

1. Pinotti JA. Saúde da Mulher. In: Planejamento Familiar. FMU, 2006. [Internet] [acesso em 2011 Ago 14]. Disponível em: http://fmu.br/pdf/ cap06_a.pdf

2. Brasil. Lei do planejamento familiar. Lei $n^{\circ}$ 9.263, de 12 de Janeiro de 1996. [Internet] [acesso em 2007 Abr 01]. Disponível em: http://www. planalto.gov.br/ccivil_03/Leis/L9263.htm

3. FEBRASGO. Anticoncepção: manual de orientação. São Paulo: Ponto; 2004.

4. Steiner MJ, Trussel J, Mehta N, Condon S, Subramaniam S, et al. Communicating contraceptive effectiveness: A randomized controlled trial to inform a World Health Organization family planning handbook. Am J Obstet Gynecol. 2006; 195(1): 85-91. http://dx.doi.org/10.1016/j. ajog.2005.12.053

5. Al-Riyami A, Afifi M, Mabry RM. Women's autonomy, education and employment in Oman and their influence on contraceptive use. Reprod Health Matters. 2004; 12(23): 144-54. http://dx.doi.org/10.1016/S09688080(04)23113-5

6. Scott A, Glasier A. Evidence based contraceptive choices. Best Pract Res Clin Obstet Gynaecol. 2006; 20(5): 665-80. http://dx.doi.org/10.1016/j. bpobgyn.2006.03.002

7. Carvalho MLO, Pirotta KCM, Schor N. Participação masculina na contracepção pela ótica feminina. Rev Saúde Pública. 2001; 35(1): 23 31. http://dx.doi.org/10.1590/S0034-89102001000100004 
8. Ballone GJ. Gravidez na adolescência. In: PsiqWeb. [Internet] [acesso em 2011 Ago 14]. Disponível em: http://gballone.sites.uol.com.br/infantil/ adolesc3.htm

9. Yazlle MEHD. Gravidez na adolescência. Rev Bras Ginecol. 2006; 28(8): 443-4. http://dx.doi.org/10.1590/S0100-72032006000800001

10. Manning WD, Longmore MA, Giordano PC. The relationship context of contraceptive use at first intercourse. Fam Plann Perspect. 2000; 32(3): 104-10.

11. Zenevicz L, Fernandes FC. Sexualidade do adolescente e DST/Aids: conhecimentos, atitudes e praticas em escolares de Concordia, SC. J Bras Aids. 2006; 7(5): 231-7.

12. Thiebaux HJ. Self-prescribed contraceptive education by the unwillingly pregnant. Am J Public Health. 1972; 62(5): 689-94.

13. Secretaria de Esporte, Lazer e Juventude do Estado de São Paulo. Juventude SP. Notícias. Número de adolescentes grávidas cai em São Paulo. 2010. [Internet] [acesso em 2011 Ago 14]. Disponível em: http://www.juventude. sp.gov.br/sis/lenoticia. .php?id=2503

14. Araújo FM. Ações de Educação em Saúde no Planejamento Familiar nas Unidades de Saúde da Família do Município de Campina Grande - PB. UEPB; 2004. 71p.

15. Sadovszky V, Kovar CK, Brown C, Armbruster M. The need for sexual health information: perceptions and desires of young adults. MCN Am J Matern Child Nurs. 2006; 31(6): 373-80.

16. Lindsay J, Smith AM, Rosenthal DA. Conflicting advice? Australian adolescents' use of condoms or the pill. Fam Plann Perspect. 1999; 31(4): 190-4.

17. Lyra J. Paternidade na adolescência: percorrendo a bibliografia. Anais do XI Encontro de Estudos Populacionais da ABEP Caxambu. Unicamp: 2000;1. [Internet] [acesso em 2007 Maio 20]. Disponível em: http://www.abep.nepo. unicamp.br/docs/anais/pdf/2000/Todos/Posteres/Paternidade\%20na\%20 Adolesc\%C3\%AAncia\%20-\%20Percorrendo\%20a\%20bibliografia.pdf

18. Weber LND, Santos CSD, Becker C, Santos TP. Filhos em creches no século XXI e os sentimentos das mães. Psicol Arg. 2006; 24(44): 45-54. [Internet] [acesso em 2011 Dez 23]. Disponível em: http://www2.pucpr.br/reol/index. php/PA?dd1 $=137 \&$ dd99=pdf

19. Bussato ARM, Oliveira AP, Carvalho HSL. A influência do aleitamento materno sobre o estado nutricional de crianças e adolescentes. Rev Paul Pediatr. 2006; 24(3): 249-54.
20. Brasil. Programa de Atenção à Saúde do Adolescente. Adolescente saudável - a saúde de braços abertos. Brasília: Ministério da Saúde; 2004.

21. Gil AC. Métodos e técnicas de pesquisa social. São Paulo: Atlas; 1999.

22. Brasil. Pré-natal e puerpério: atenção qualificada e humanizada. Normas e manuais técnicos: série direitos sexuais e reprodutivos. Caderno n 5. Brasília: Ministério da Saúde; 2005.

23. Vitale MSS, Amâncio OMS. Gravidez na adolescência. BNP. 2001 3(3). [Internet] [acesso em 2011 Ago 14]. Disponível em: http://www. pjpp.sp.gov.br/2004/artigos/11.pdf

24. Cardozo DM, Freitas IC, Fontoura MSH. Comportamento sexual de adolescentes do gênero feminino de estratos sociais distintos em Salvador, Bahia, Brasil. Rev Paul Pediatr. 2002; 20(3): 122-8.

25. Topsever P, Filiz M, Aladag N, Topalli R, Cigerli O, Görpelioğlu S. Counselling and knowledge about contraceptive mode of action among married women; a cross-sectional study. BMC Women's Health. 2006; 6: 12. http://dx.doi.org/10.1186/1472-6874-6-12

26. Belo MAV, Silva JLP. Conhecimento, atitude e prática sobre métodos anticoncepcionais entre adolescentes gestantes. Rev Saúde Pública. 2004; 38(4):479-87. http://dx.doi.org/10.1590/S003489102004000400001

27. Saito MI, Leal MM. O exercício da sexualidade na adolescência: a contracepção em questão. Pediatria. 2003; 25(1/2): 36-42.

28. Dias-da-Costa JS, Gigante DP, Menezes AMB, Olinto MTA, Macedo $S$, Britto MAP, et al. Uso de métodos anticoncepcionais e adequação de contraceptivos hormonais orais na cidade de Pelotas, Rio Grande do Sul, Brasil: 1992 e 1999. Cad Saúde Pública. 2002; 18(1). [online] http://dx.doi.org/10.1590/S0102-311X2002000100010

29. Souza JMM, Pelloso SM, Uchimura NS, Souza F. Utilização de métodos contraceptivos entre as usuárias da rede pública de saúde do município de Maringá-PR. Rev Bras Ginecol Obstet. 2006; 28 (5): 271-7. http://dx.doi.org/10.1590/S0100-72032006000500002

30. Carreno I, Dias-da-Costa JS, Olinto MTA, Meneghel S. Uso de métodos contraceptivos entre mulheres com vida sexual ativa em São Leopoldo, Rio Grande do Sul, Brasil. Cad Saúde Pública. 2006; 22(5): 1101-9. http://dx.doi.org/10.1590/S0102-311X20060005000237 